Article

\title{
First Mitochondrial Genome from Nemouridae (Plecoptera) Reveals Novel Features of the Elongated Control Region and Phylogenetic Implications
}

\author{
Zhi-Teng Chen ${ }^{1}$ and Yu-Zhou Du ${ }^{1,2, *}$ \\ 1 School of Horticulture and Plant Protection \& Institute of Applied Entomology, Yangzhou University, \\ Yangzhou 225009, China; wstcczt@gmail.com \\ 2 Joint International Research Laboratory of Agriculture and Agri-Product Safety, \\ The Ministry of Education, Yangzhou University, Yangzhou 25009, China \\ * Correspondence: yzdu@yzu.edu.cn; Tel.: +86-514-8797-1854
}

Academic Editor: Stephen A. Bustin

Received: 20 April 2017; Accepted: 4 May 2017; Published: 5 May 2017

\begin{abstract}
The complete mitochondrial genome (mitogenome) of Nemoura nankinensis (Plecoptera: Nemouridae) was sequenced as the first reported mitogenome from the family Nemouridae. The $N$. nankinensis mitogenome was the longest $(16,602 \mathrm{bp})$ among reported plecopteran mitogenomes, and it contains 37 genes including 13 protein-coding genes (PCGs), 22 transfer RNA (tRNA) genes and two ribosomal RNA (rRNA) genes. Most PCGs used standard ATN as start codons, and TAN as termination codons. All tRNA genes of $N$. nankinensis could fold into the cloverleaf secondary structures except for trnSer (AGN), whose dihydrouridine (DHU) arm was reduced to a small loop. There was also a large non-coding region (control region, CR) in the N. nankinensis mitogenome. The $1751 \mathrm{bp} C \mathrm{C}$ was the longest and had the highest $\mathrm{A}+\mathrm{T}$ content $(81.8 \%)$ among stoneflies. A large tandem repeat region, five potential stem-loop (SL) structures, four tRNA-like structures and four conserved sequence blocks (CSBs) were detected in the elongated CR. The presence of these tRNA-like structures in the CR has never been reported in other plecopteran mitogenomes. These novel features of the elongated CR in N. nankinensis may have functions associated with the process of replication and transcription. Finally, phylogenetic reconstruction suggested that Nemouridae was the sister-group of Capniidae.
\end{abstract}

Keywords: Plecoptera; stoneflies; mitochondrial genome; control region; phylogeny

\section{Introduction}

Nowadays, mitochondrial genome (mitogenome) has been one of the most popular molecules widely used in insect taxonomy, population genetics, evolutionary biology and phylogenetics [1]. Generally, an insect mitogenome is a double strand circular molecule, ranging from $14-20 \mathrm{~kb}$ in length. It usually contains a typical set of 37 genes: 13 protein-coding genes (PCGs), 22 transfer RNA (tRNA) genes and two ribosomal RNA (rRNA) genes [2,3]. There is also a non-coding control region (CR) in mitogenomes, which is involved in the initiation and regulation of transcription and replication of the mitogenome [4-6]. The CR is the most variable region concerning A+T content and length, and some structural elements are expected to be present in a CR: (1) a poly-T stretch near the $5^{\prime}$ end of the CR; (2) a poly-[TA(A) $]_{n}$ stretch following the poly-T stretch; (3) conserved stem-loop (SL) structures with a $5^{\prime}$ flanking TATA and a 3' flanking G(A) $)_{n}$ T motif; and (4) a G+A-rich region located downstream of the CR [7]. Functional information on replication derived from these structures has been well discussed, but the transcription features of insect mitogenomes are still little known [6-9]. 
The Plecoptera (stoneflies) are a group of ancient insects, which are vital in the reconstruction of the evolutionary history of insects, and they are important bioindicators of water quality [10]. To date, 15 complete or near complete plecopteran mitogenomes have been reported, and relevant attempts have been made to rebuild the phylogeny of Plecoptera based on the increasing mitogenomic data [11-24]. However, the phylogenetic position of Plecoptera in Insecta and the phylogenetic relationship among stoneflies are still controversial.

To facilitate the study of mitogenome phylogeny in Plecoptera, we report the complete mitogenome of Nemoura nankinensis, which was the first sequenced mitogenome from Nemouridae. In this study, the organization, nucleotide composition, codon usage, secondary tRNA structures, and novel features of the elongated CR in the N. nankinensis mitogenome were analyzed. Finally, the phylogenetic relationships of N. nankinensis and other stoneflies were reconstructed based on PCG sequences.

\section{Results and Discussion}

\subsection{Genome Annotation and Base Composition}

The complete mitogenome of $N$. nankinensis was 16,602 bp in length, which was larger than any other reported stonefly mitogenomes. It contained the 37 typical mitochondrial genes (13 PCGs, 22 tRNAs and two rRNAs) and a large noncoding control region; 23 genes (nine PCGs and 14 tRNAs) were located on the majority strand (J-strand) and 14 genes (four PCGs, eight tRNAs, and two rRNAs) were on the minority strand (N-strand) (Figure 1, Table 1 ). The highly-conserved gene arrangement of the N. nankinensis mitogenome was identical with other stoneflies as well as the model insect, Drosophila yakuba, which had the putative ancestral arthropod mitogenome [25]. The N. nankinensis mitogenome contained 36 overlapping nucleotides that were 1-8 bp in length and located in 11 pairs of neighboring genes. The longest overlap ( $8 \mathrm{bp}$ ) was located between trnCys and trnTrp. Except for the large control region, a total of 72 intergenic nucleotides (IGN) were found in 13 locations, ranging in size from 1 to $31 \mathrm{bp}$.

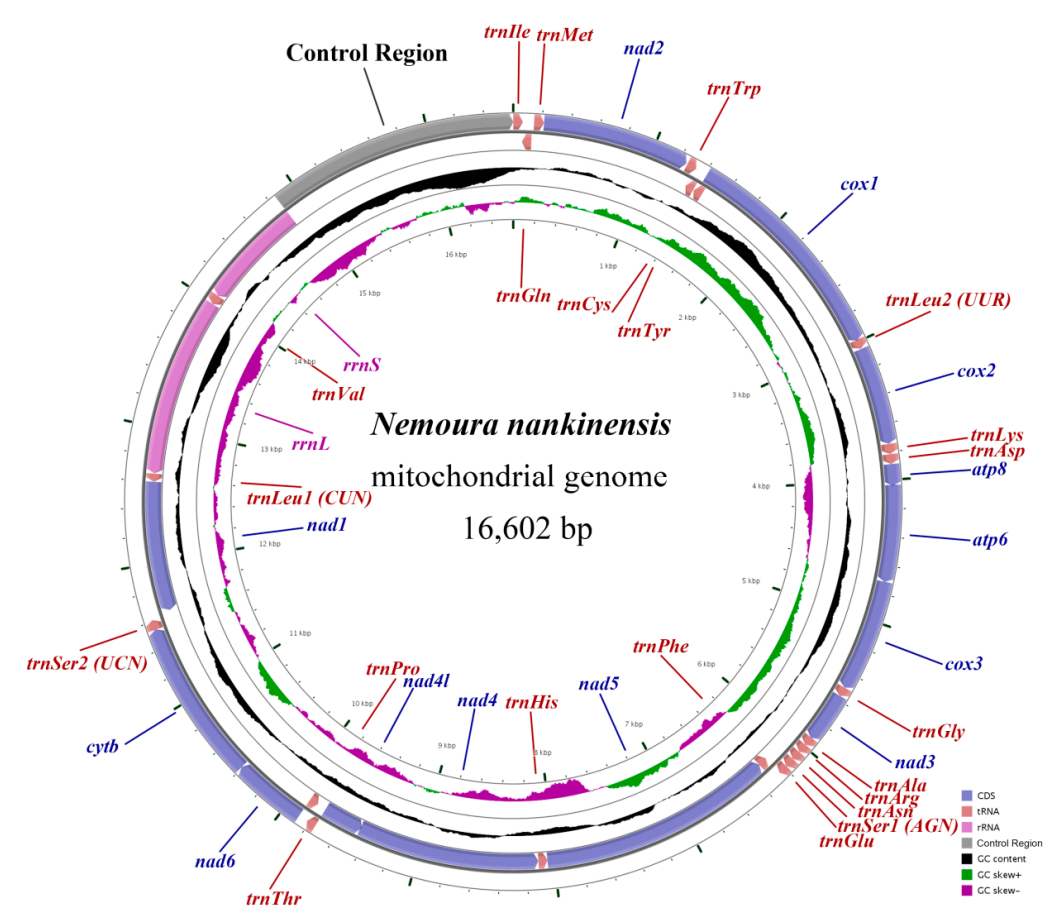

Figure 1. Mitochondrial map of Nemoura nankinensis. Genes outside the map are transcribed in a clockwise direction, whereas those inside the map are transcribed counterclockwise. The second circle shows the GC content and the third shows the GC skew. GC content and GC skew are plotted as the deviation from the average value of the entire sequence. 
Table 1. Mitochondrial genome structure of Nemoura nankinensis.

\begin{tabular}{|c|c|c|c|c|c|c|}
\hline Gene & $\begin{array}{l}\text { Position } \\
\text { (bp) }\end{array}$ & $\begin{array}{l}\text { Size } \\
\text { (bp) }\end{array}$ & Direction & $\begin{array}{c}\text { Intergenic } \\
\text { Nucleotides (IGN) }\end{array}$ & $\begin{array}{l}\text { Anti- or Start/ } \\
\text { Stop Codons }\end{array}$ & AT $\%$ \\
\hline trnIle (I) & $1-66$ & 66 & Forward & 0 & GAT & 66.7 \\
\hline $\operatorname{trn} G \ln (Q)$ & $64-132$ & 69 & Reverse & -3 & TTG & 78.3 \\
\hline $\operatorname{trnMet}(M)$ & $146-214$ & 69 & Forward & 13 & CAT & 62.3 \\
\hline nad2 & 215-1249 & 1035 & Forward & 0 & ATG/TAA & 70.8 \\
\hline $\operatorname{trn} \operatorname{Trp}(W)$ & $1259-1327$ & 69 & Forward & 9 & TCA & 69.6 \\
\hline $\operatorname{trnCys}(\mathrm{C})$ & $1320-1382$ & 63 & Reverse & -8 & GCA & 68.3 \\
\hline $\operatorname{trnTyr}(Y)$ & $1388-1453$ & 66 & Reverse & 5 & GTA & 60.6 \\
\hline $\operatorname{cox} 1$ & $1450-2983$ & 1534 & Forward & -2 & CCG/T- & 64.1 \\
\hline trnLeu2 (UUR) & 2986-3052 & 67 & Forward & 0 & TAA & 68.7 \\
\hline $\operatorname{cox} 2$ & $3056-3743$ & 688 & Forward & 3 & ATG/T- & 67.2 \\
\hline trnLys $(K)$ & $3745-3815$ & 71 & Forward & 1 & CTT & 64.8 \\
\hline $\operatorname{trn} A s p(D)$ & $3817-3885$ & 69 & Forward & 1 & GTC & 73.9 \\
\hline atp 8 & $3886-4044$ & 159 & Forward & 0 & ATT/TAA & 76.7 \\
\hline atp6 & $4038-4715$ & 678 & Forward & -7 & ATG/TAA & 67.7 \\
\hline $\cos 3$ & $4715-5503$ & 789 & Forward & -1 & ATG/TAA & 64.9 \\
\hline $\operatorname{trn} G l y(G)$ & $5504-5569$ & 66 & Forward & 0 & TCC & 72.7 \\
\hline nad3 & $5570-5923$ & 354 & Forward & 0 & ATT/TAG & 72.0 \\
\hline $\operatorname{trnAla}(A)$ & $5922-5985$ & 64 & Forward & -2 & TGC & 70.3 \\
\hline $\operatorname{trn} A r g(R)$ & $5986-6049$ & 64 & Forward & 0 & TCG & 64.1 \\
\hline $\operatorname{trn} A s n(N)$ & $6052-6117$ & 66 & Forward & 2 & GTT & 72.7 \\
\hline $\operatorname{trnSer1}(A G N)$ & 6118-6184 & 67 & Forward & 0 & GCT & 67.2 \\
\hline $\operatorname{trnGlu}(E)$ & $6185-6250$ & 66 & Forward & 0 & TTC & 90.9 \\
\hline trnPhe $(F)$ & $6249-6315$ & 67 & Reverse & -2 & GAA & 67.2 \\
\hline nad5 & $6316-8050$ & 1735 & Reverse & 0 & ATG/T- & 70.7 \\
\hline trnHis $(H)$ & $8051-8117$ & 67 & Reverse & 0 & GTG & 79.1 \\
\hline nad4 & 8119-9459 & 1341 & Reverse & 1 & ATG/TAA & 71.5 \\
\hline nad4l & $9453-9749$ & 297 & Reverse & -7 & ATG/TAA & 74.7 \\
\hline $\operatorname{trnThr}(\mathrm{T})$ & 9752-9817 & 66 & Forward & 2 & TGT & 80.3 \\
\hline trnPro $(P)$ & 9817-9882 & 66 & Reverse & -1 & TGG & 71.2 \\
\hline nad6 & 9884-10408 & 525 & Forward & 1 & ATT/TAA & 73.3 \\
\hline$C y t b$ & 10408-11544 & 1137 & Forward & -1 & ATG/TAG & 66.8 \\
\hline trnSer2 (UCN) & 11543-11612 & 70 & Forward & -2 & TGA & 74.3 \\
\hline nad1 & 11644-12594 & 951 & Reverse & 31 & TTG/TAA & 69.4 \\
\hline trnLeu1 (CUN) & $12596-12661$ & 66 & Reverse & 1 & TAG & 75.8 \\
\hline$r r n L$ & $12664-13990$ & 1327 & Reverse & 2 & & 74.9 \\
\hline $\operatorname{trnVal}(\mathrm{V})$ & 13991-14061 & 71 & Reverse & 0 & TAC & 69.0 \\
\hline$r r n S$ & $14062-14851$ & 790 & Reverse & 0 & & 71.3 \\
\hline Control region & $14852-16602$ & 1751 & & 0 & & 81.8 \\
\hline
\end{tabular}

In the N. nankinensis mitogenome, the $\mathrm{A}+\mathrm{T}$ content of the whole mitogenome, PCGs, tRNAs, rRNAs and the control region was $71.2 \%, 69.0 \%, 71.4 \%, 73.5 \%$ and $81.9 \%$, respectively (Table 2). For the 37 genes, the $\mathrm{A}+\mathrm{T}$ content ranged from $60.6 \%$ in trnTyr to $90.9 \%$ in trnGlu, showing a bias for the $\mathrm{A}$ and T nucleotides. The AT skew and GC skew of the N. nankinensis mitogenome were calculated and showed a biased use of A and C nucleotides (Table 2). For the J-strand, the AT skew of PCGs was negative and the GC skew of tRNA genes was positive, which was inconsistent with the strand bias of most other insects (positive AT skew and negative GC skew for the J-strand) [26]. 
Table 2. Nucleotide composition of the Nemoura nankinensis mitogenome.

\begin{tabular}{|c|c|c|c|c|c|c|c|c|}
\hline \multirow{2}{*}{ Regions } & \multicolumn{6}{|c|}{ Nucleotides Proportions (\%) } & \multirow{2}{*}{ AT Skew } & \multirow{2}{*}{ GC Skew } \\
\hline & A & $\mathbf{T}$ & G & $\mathrm{C}$ & $\mathrm{A}+\mathrm{T}$ & $\mathrm{G}+\mathrm{C}$ & & \\
\hline Whole genome & 37.2 & 34.0 & 11.8 & 17.0 & 71.2 & 28.8 & 0.04 & -0.18 \\
\hline Protein coding genes & 35.7 & 33.3 & 12.9 & 18.1 & 69.0 & 31.0 & 0.03 & -0.17 \\
\hline 1st codon position & 40.5 & 29.3 & 14.4 & 15.8 & 69.8 & 30.2 & 0.16 & -0.05 \\
\hline 2nd codon position & 31.5 & 32.2 & 15.3 & 21.0 & 63.7 & 36.3 & -0.01 & -0.16 \\
\hline 3rd codon position & 35.1 & 38.3 & 9.1 & 17.5 & 73.4 & 26.6 & -0.04 & -0.32 \\
\hline Protein coding genes-J & 29.7 & 38.0 & 14.1 & 18.2 & 67.7 & 32.3 & -0.12 & -0.13 \\
\hline 1st codon position & 30.5 & 35.0 & 17.6 & 16.9 & 65.5 & 34.5 & -0.07 & 0.02 \\
\hline 2nd codon position & 26.4 & 40.5 & 12.5 & 20.6 & 66.9 & 33.1 & -0.21 & -0.24 \\
\hline 3rd codon position & 32.2 & 38.5 & 12.2 & 17.1 & 70.7 & 29.3 & -0.09 & -0.17 \\
\hline Protein coding genes-N & 45.3 & 25.6 & 11.1 & 18.0 & 70.9 & 29.1 & 0.28 & -0.24 \\
\hline 1st codon position & 46.9 & 26.2 & 9.7 & 17.2 & 73.1 & 26.9 & 0.28 & -0.28 \\
\hline 2nd codon position & 45.7 & 25.5 & 11.0 & 17.8 & 71.2 & 28.8 & 0.28 & -0.24 \\
\hline 3rd codon position & 43.2 & 25.2 & 12.6 & 19.0 & 68.4 & 31.6 & 0.26 & -0.20 \\
\hline tRNA genes & 36.8 & 34.6 & 12.8 & 15.8 & 71.4 & 28.6 & 0.03 & -0.10 \\
\hline tRNA genes-J & 36.4 & 34.9 & 14.7 & 14.0 & 71.3 & 28.7 & 0.02 & 0.02 \\
\hline tRNA genes-N & 37.7 & 33.8 & 9.1 & 19.4 & 71.5 & 28.5 & 0.05 & -0.36 \\
\hline rRNA genes & 40.3 & 33.2 & 9.6 & 16.9 & 73.5 & 26.5 & 0.10 & -0.28 \\
\hline Control region & 43.2 & 38.7 & 6.4 & 11.7 & 81.9 & 18.1 & 0.05 & -0.29 \\
\hline
\end{tabular}

\subsection{Protein-Coding Genes, Transfer RNA and Ribosomal RNA Genes}

The 13 PCGs of N. nankinensis were similar in length and arrangement to other sequenced stonefly mitogenomes. Eleven PCGs initiated with the standard start codon ATN (ATT and ATG), while cox1 used CCG, and nad1 used TTG as a start codon. Ten PCGs had complete termination codons (TAA or TAG), whereas cox1, $\operatorname{cox} 2$ and nad5 ended with the incomplete termination codon $\mathrm{T}$, which could be completed by post-transcriptional polyadenylation [27]. The relative synonymous codon usage (RSCU) values of the $N$. nankinensis mitogenome were calculated and illustrated, indicating the five most frequently used codons: TTA (Leu), CGA (Arg), GTA (Val), AAA (Lys) and CAA (Gln) (Figure 2).

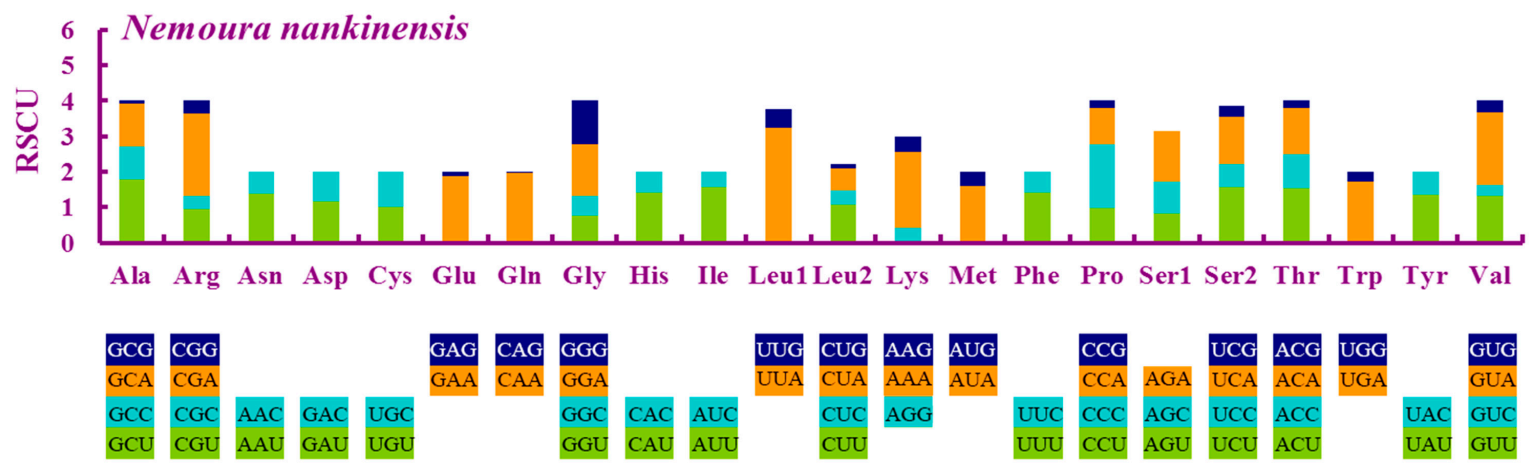

Figure 2. Relative synonymous codon usage (RSCU) in the Nemoura nankinensis mitogenome. Codon families are indicated below the $X$-axis.

The total length of the 22 tRNA genes was $1404 \mathrm{bp}$, and individual genes ranged from 63 to $71 \mathrm{bp}$ with an average $\mathrm{A}+\mathrm{T}$ content of $71.4 \%$. All tRNA genes of N. nankinensis were predicted to fold into typical cloverleaf secondary structures (Figure 3). However, in $\operatorname{trnSer}(A G N)$, the dihydrouridine (DHU) arm was reduced to a small loop, which was common in many other metazoan mitogenomes [28]. In addition, 30 mismatched base pairs were identified in the tRNA genes, and these were all G-U pairs. In N. nankinensis, the anticodons of the 22 tRNAs were identical with other stoneflies, and the AGG codon was translated as Lys instead of Ser, which indicated the utilization of a variant of the 
invertebrate mitochondrial genetic code in this mitogenome (Table 1). This phenomenon has been well discussed by Abascal et al., and the shifts between alternative genetic codes were concluded to occur frequently within arthropod main lineages $[29,30]$.
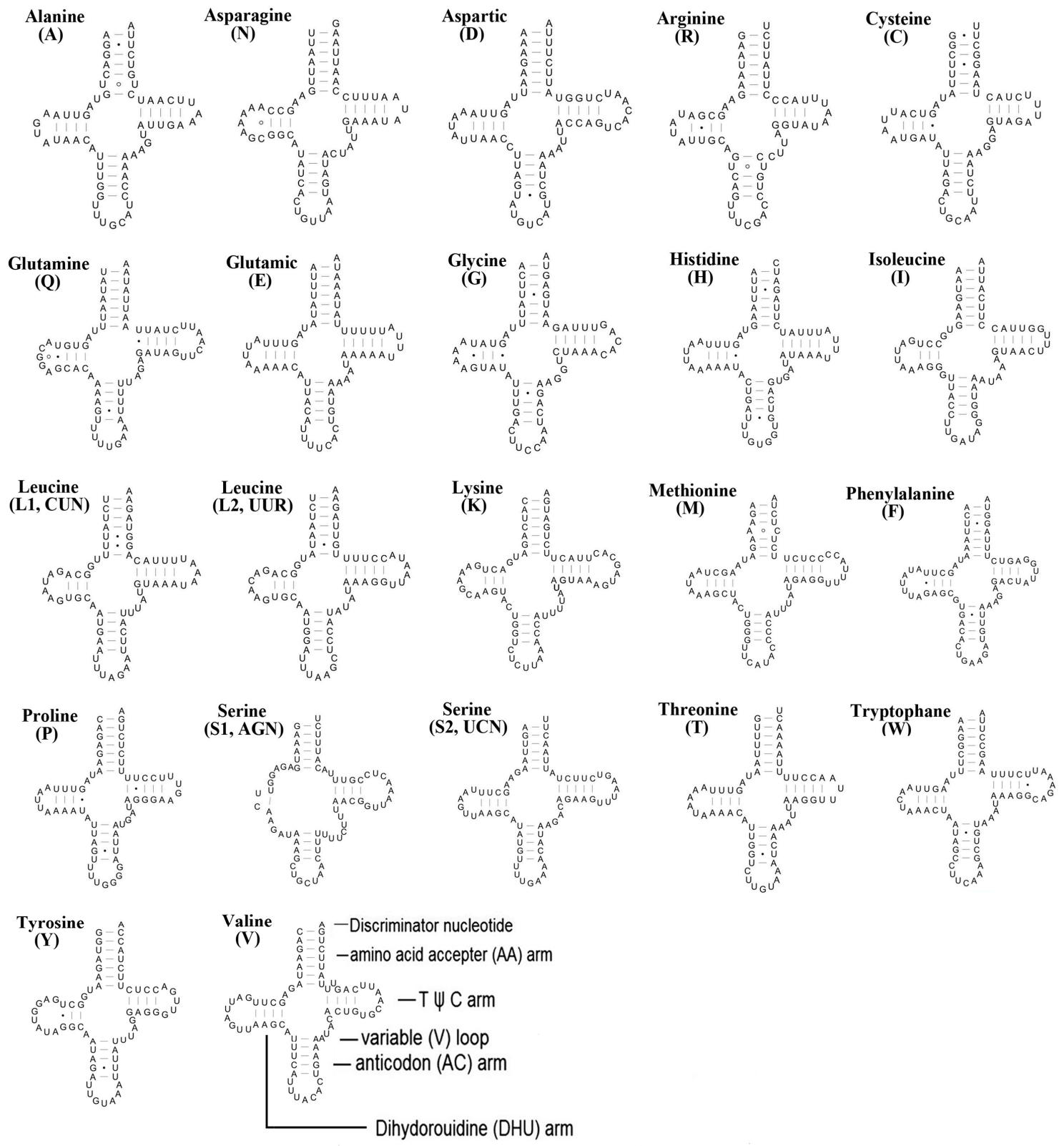

Figure 3. Inferred secondary structures of tRNAs from the Nemoura nankinensis mitogenome. The tRNAs are labelled with the abbreviations of their corresponding amino acids. Structural elements in tRNA arms and loops are illustrated as for $\operatorname{trn} V$. Dashes (-) indicate Watson-Crick bonds, dots (.) indicate mistaken bonds, and circles $\left(^{\circ}\right)$ indicate loops in arms.

The large ribosomal RNA ( $r r n L)$ gene of $N$. nankinensis was $1327 \mathrm{bp}$ in length with an A+T content of $74.9 \%$, and the small ribosomal RNA ( $r r n S)$ gene was $790 \mathrm{bp}$ with an A+T content of $71.3 \%$ (Table 1). The two rRNA genes were mapped between trnLeu (CUN) and the control region, which was consistent with other stonefly species. 


\subsection{The Control Region}

The control region (CR) of the N. nankinensis mitogenome is currently the longest known CR (1751 bp) with the highest A+T content (81.8\%) among stoneflies, and was located at the conserved position between $r r n S$ and trnIle (Figure 1, Tables 1 and 3). Firstly, a large repeat region (15021-16049) was identified, which was 1029 bp and contained 3.1 tandem repeats (Figure 4). Each of the three repeated sequences could be folded into a same trnAsn-like structure encoded on the N-strand. These long tandem repeats might explain the large size of the CR in N. nankinensis.

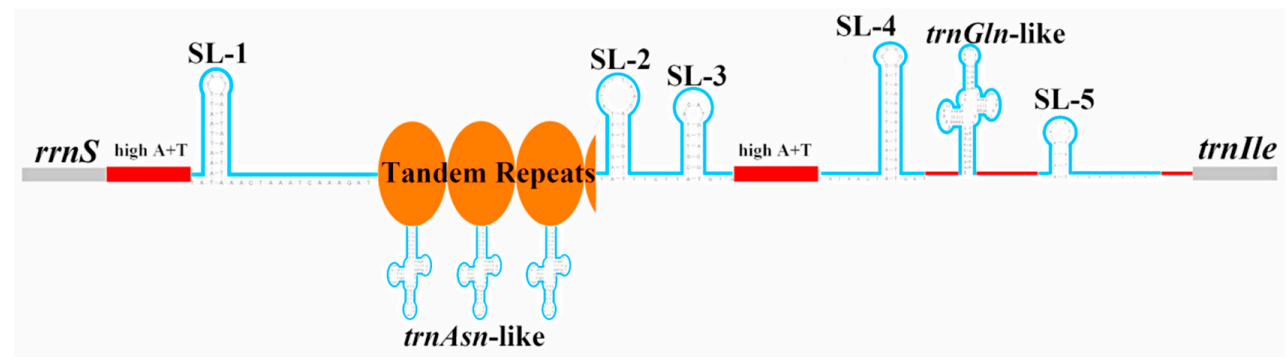

Figure 4. Predicted structural elements in the control region of Nemoura nankinensis. Tandem repeat units are indicated by orange ellipses. Stem-loop (SL) and tRNA-like structures are demarcated by blue lines. Other A+T-rich sequences are shown as red lines.

Table 3. Comparison of mitogenome size and control region size with $\mathrm{A}+\mathrm{T}$ content among stoneflies.

\begin{tabular}{ccccc}
\hline Species & $\begin{array}{c}\text { Mitogenome } \\
\text { Size (bp) }\end{array}$ & $\begin{array}{c}\text { Control Region } \\
\text { Size (bp) }\end{array}$ & $\begin{array}{c}\text { A+T Content of } \\
\text { Control Region (\%) }\end{array}$ & $\begin{array}{c}\text { Accession } \\
\text { Number }\end{array}$ \\
\hline N. nankinensis & 16,602 & 1751 & 81.8 & KY940360 \\
C. zijinshana & 16,310 & 1513 & 62.0 & KX094942 \\
M. arizonensis & 14,921 & $\mathrm{~N} / \mathrm{A}$ & $\mathrm{N} / \mathrm{A}$ & KP642637 \\
A. tikumana & 15,564 & $\mathrm{~N} / \mathrm{A}$ & $\mathrm{N} / \mathrm{A}$ & $\mathrm{KR} 604721$ \\
Styloperla sp. & 15,416 & $\mathrm{~N} / \mathrm{A}$ & 77.3 & $\mathrm{~K} 088971$ \\
S. spinicercia & 16,129 & 1259 & 80.2 & $\mathrm{KX} 845569$ \\
Cryptoperla sp. & 15,633 & 777 & 80.1 & KM952026 \\
S. longistyla & 16,151 & 1107 & 81.3 & $\mathrm{AY} 6878666$ \\
P. princeps & 16,004 & 1158 & 68.9 & KU182360 \\
P. badia & 15,586 & 687 & 74.5 & KF484757 \\
D. cephalotes & 15,666 & 711 & 73.3 & KM199685 \\
A. hainana & 15,804 & 899 & 78.0 & KM409708 \\
Togoperla sp. & 15,723 & 780 & 78.2 & KC894944 \\
K. wangi & 16,179 & 1251 & 79.1 & KT186102 \\
K. chungnanshana & 15,943 & 1062 & N/A & AY142073 \\
Peltoperla arcuata & N/A & 1072 & & \\
\hline
\end{tabular}

N/A: data not available.

Then five SL structures were predicted in the CR: SL-1 (14,982-15,022), SL-2 (16,064-16,088), SL-3 $(16,089-16,110)$, SL-4 $(16,368-16,407)$ and SL-5 $(16,552-16,572)$. The proposed "G(A) ${ }_{n} \mathrm{~T}^{\text {" motif }}$ was detected after SL-1 and SL-4, but it was modified as "GTA" after SL-2 and SL-3, and "TGA" after SL-5. These SL structures were considered to be associated with the initiation of mitogenome replication and transcription [31]. Interestingly, a trn Gln-like structure was found between SL-4 and SL-5, and it was encoded on the majority strand. The presence of tRNA-like structures in the CR has never been reported in other plecopteran mitogenomes, and its underlying mechanisms are unclear. These tRNA-like structures may have signaling functions in the process of transcription [32]. When compared with the available 11 CRs of the other stoneflies, four conserved sequence blocks (CSBs) were identified in N. nankinensis (Figure 5). These CBSs ranged in size from 35 to $100 \mathrm{bp}$, and their sequence identity among species was generally over 50\% (Figure 5). However, the function of these CSBs is still unclear. 


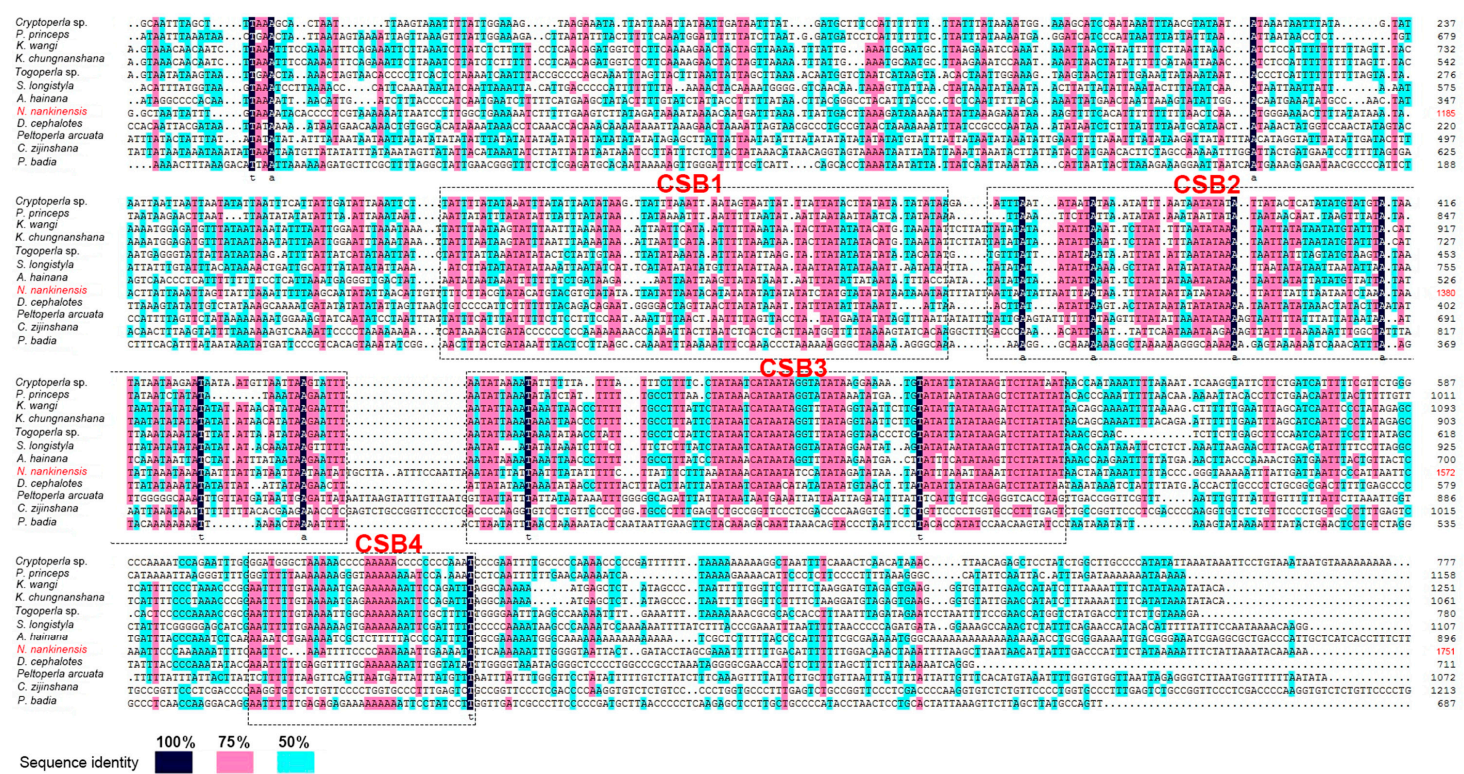

Figure 5. The alignment of conserved structural elements of CRs among stoneflies. Sequence identity among species was indicated by colored boxes. CSB1-4 indicates four conserved sequence blocks in the CRs.

In the past, the sequenced stonefly mitogenomes were mainly from the superfamily group Systellognatha, only N. nankinensis and the three Capniidae species are from the group Euholognatha. The CR of the Capnia zijinshana (Plecoptera: Capniidae) mitogenome was completely reported, and was $1513 \mathrm{bp}$ in length, the second longest in stoneflies. Accordingly, we speculate that with more mitogenomes sequenced from Plecoptera, especially from the group Euholognatha, highly varied mitogenome sizes with more novel structural features will be found, and their functions and phylogenetic implications will be clear.

\subsection{Phylogenetic Analyses}

The phylogenetic analyses were performed based on the concatenated nucleotide sequences of 13 PCGs derived from 14 available stonefly mitogenomes, and one Ephemeroptera species was included as the outgroup (Table 3). BI and ML analyses generated similar tree topologies (Figures 6 and 7). In both analyses, N. nankinensis was recovered as the sister group of the three species from Capniidae, and the species from other five families were grouped together. This corresponds with the taxonomical knowledge that both Nemouridae and Capniidae are members in the superfamily group Euholognatha, while other five families are from Systellognatha in Plecoptera. In addition to the Capniidae, the clade containing species from Perlidae was well supported on both trees. However, the phylogenetic positions of the four families, Pteronarcyidae, Choloroperlidae, Styloperlidae and Peltoperlidae, were still unclear. These results were generally identical to the recent study made by Chen and $\mathrm{Du}$ [12]. The uncertainty and inconsistency of recent mitogenomic phylogenetic studies in Plecoptera may result from the limited mitogenomic data, and more sequencing work is necessary to resolve this problem. 


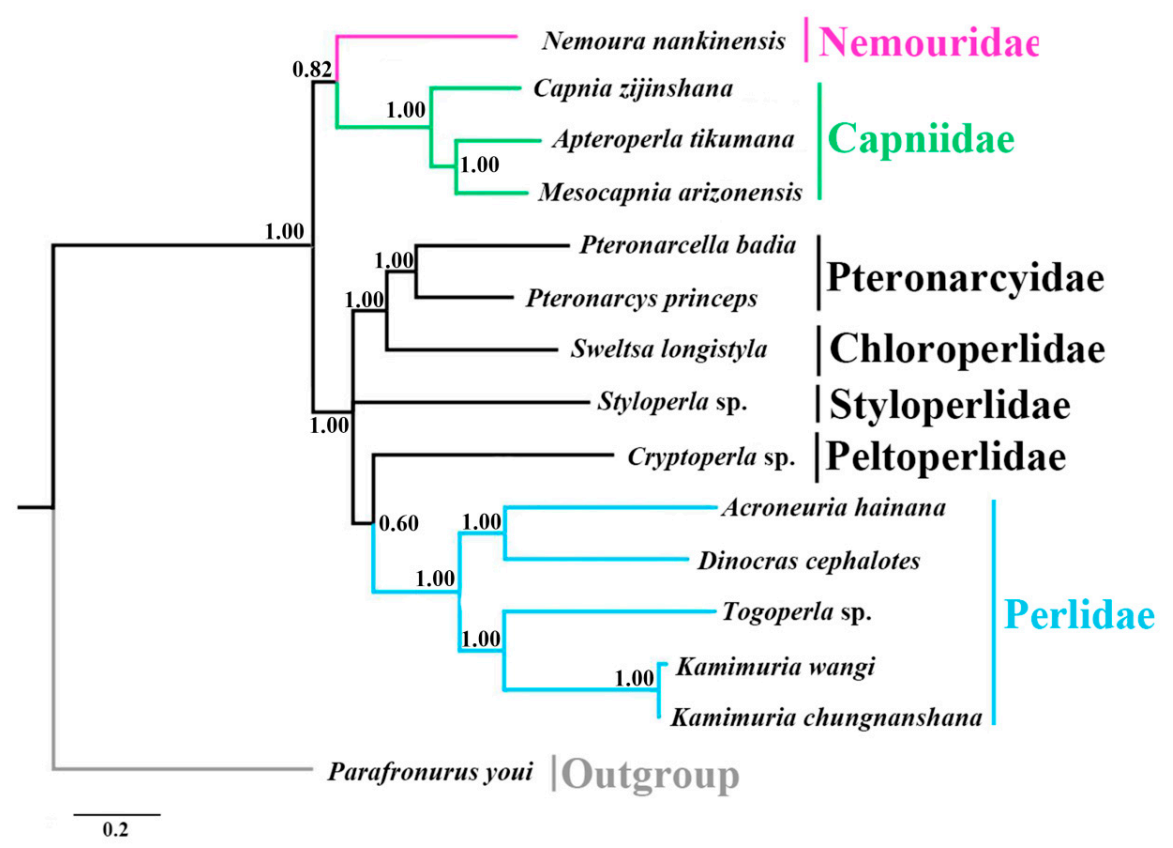

Figure 6. Phylogenetic relationships among stoneflies inferred by Bayesian inference. Numbers at the nodes are posterior probabilities. The family names are listed after the species. The tree was rooted with one outgroup, Parafronurus youi.

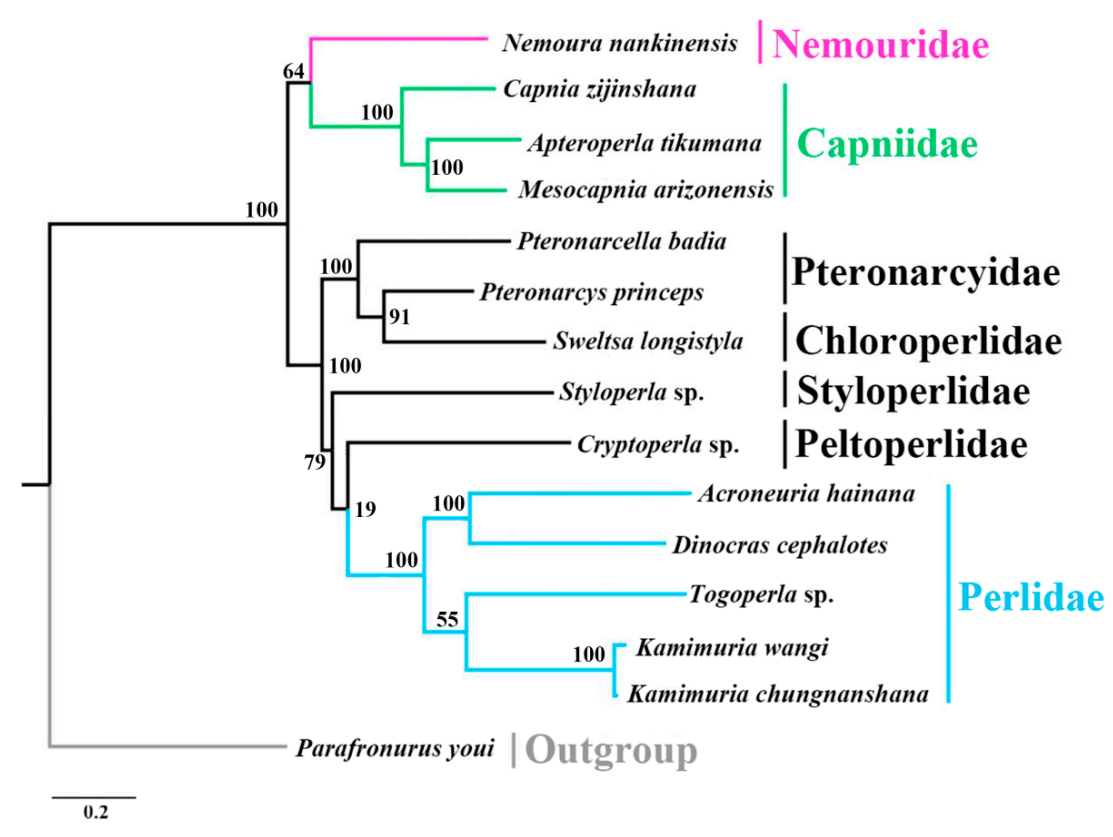

Figure 7. Phylogenetic relationships among stoneflies inferred by maximum likelihood analysis. Numbers at the nodes are bootstrap values. Family names are shown after the species. The tree was rooted with one outgroup, Parafronurus youi.

\section{Materials and Methods}

\subsection{Sample Preparation and DNA Extraction}

Specimens of N. nankinensis were collected in February 2016 from Zijin Mountain of Jiangsu Province, China. Our research activities were not banned by any organization or individual and did not involve endangered or protected species. Specimens used in this study were identified and 
preserved in $100 \%$ ethanol and stored at $-20{ }^{\circ} \mathrm{C}$. Genomic DNA was extracted from adults using the Column mtDNAout kit (Tianda, Beijing, China) and stored at $-20^{\circ} \mathrm{C}$ until used for PCR.

\subsection{PCR Amplification and Sequencing}

Five pairs of LA-PCR primers were used to amplify segments of the N. nankinensis mitogenome (Table A1). Conditions for LA-PCR amplification were as follows: initial denaturation at $93{ }^{\circ} \mathrm{C}$ for $2 \mathrm{~min}$, followed by 40 cycles at $92{ }^{\circ} \mathrm{C}$ for $10 \mathrm{~s}$; annealing at $54{ }^{\circ} \mathrm{C}$ for $30 \mathrm{~s}$; and elongation at $68^{\circ} \mathrm{C}$ for $8 \mathrm{~min}$ (20 cycles), which increased $20 \mathrm{~s} /$ cycle in the final 20 cycles; and final elongation at $68^{\circ} \mathrm{C}$ for $10 \mathrm{~min}$. PCR products were separated by 1.0\% agarose gel electrophoresis and purified with an Axygen DNA Gel Extraction Kit (Axygen Biotechnology, Hangzhou, China). All PCR fragments were sent to Map Biotech Company (Shanghai, China) for sequencing. Firstly, the LA-PCR fragments were partially sequenced by Shotgun sequencing in combination with the primer walking strategy (Table A1). Then 15 specifically designed primer pairs were used for the remaining gaps including the $C R$ (Table A1).

\subsection{Mitogenome Assembly, Annotation and Analyses}

The software CodonCode Aligner (http:/ / www.codoncode.com/aligner/) was used for sequence assembly. PCGs and rRNA genes were identified by comparison with the previously sequenced stonefly mitogenomes, and the gene boundaries were confirmed with ORF finder (https://www. ncbi.nlm.nih.gov/orffinder/). The mitogenomic map was depicted with CGView Server (http:// stothard.afns.ualberta.ca/cgview_server/) [33]. The tRNAs were identified by the online server MITOS combined with ARWEN (http://mbio-serv2.mbioekol.lu.se/ARWEN/) [34,35]. The secondary structure of tRNA genes was also obtained from MITOS. The nucleotide composition was analyzed by MEGA v. 6.0 [36]. Composition skew analysis was performed using the formulas AT-skew = $[\mathrm{A}-\mathrm{T}] /[\mathrm{A}+\mathrm{T}]$ and $\mathrm{GC}$-skew $=[\mathrm{G}-\mathrm{C}] /[\mathrm{G}+\mathrm{C}][37]$. The tandem repeats in the putative control region were analyzed with the Tandem Repeats Finder program (http://tandem.bu.edu/trf/trf.advanced. submit.html) and the stem-loop structures were predicted by Quikfold (http:/ / unafold.rna.albany. edu/?q=DINAMelt/Quickfold) [38]. Sequence data were deposited into GenBank under accession number KY940360.

\subsection{Phylogenetic Analyses}

Phylogenetic analyses were based on nucleotide sequence data of 13 PCGs derived from $N$. nankinensis and 13 other stonefly mitogenomes available from GenBank (Table 3). Parafronurus youi (Accession No. EU349015) from the insect order Ephemeroptera was used as the outgroup. The nucleotide sequences of the 13 PCGs were aligned with Clustal X as implemented in MEGA v. 6.0 using default settings before concatenation excluding the stop codon [39]. The length of the alignment was 11,154 nucleotides in the final dataset. The best nucleotide substitution model was determined with MEGA v. 6.0 using the Bayesian Information Criterion (BIC) and the GTR+G+I model was predetermined for analyses. Bayesian inferences (BI) and maximum likelihood (ML) analysis were respectively performed using MrBayes v. 3.1.2 [40] and the RAxML Web-Server (http://embnet.vital-it.ch/raxml-bb/index.php) [41]. The BI analyses were performed under the following conditions: 3 million generations with sampling every 100 generations, four chains (one cold chain and three hot chains) and a burn-in of $25 \%$ trees. After 3 million generations, all runs reached in stationarity were examined by Tracer v. 1.5 (effective sample sizes exceed 200) [42]. The confidence values of the BI tree were shown as Bayesian posterior probabilities. One thousand bootstrap replicates were performed with the GTRGAMMA substitution model in ML analyses. Finally, the phylogenetic trees were drawn with the software FigTree v. 1.4.2 [43].

\section{Conclusions}

The mitogenome of $N$. nankinensis was the longest among reported stonefly mitogenomes. The gene arrangement of the N. nankinensis mitogenome was highly-conserved and identical with other 
stoneflies. In the elongated CR, novel features were found, including a large tandem repeat region, five SL structures, four tRNA-like structures and four CSBs. These structural elements may have functions associated with the process of replication and transcription. Phylogenetic analyses supported that Nemouridae was the sister-group of Capniidae, which was consistent with former researches.

Acknowledgments: We express our deep gratitude to the Testing Center of Yangzhou University. This research was supported by the National Natural Science Foundation of China (31572295), the Scientific Innovation Research of the Graduate College in Jiangsu Province, China (KYZZ16_0494), and Key Laboratory of Prevention and Control of Biological Hazard Factors (Animal Origin) for Agrifood Safety and Quality, Ministry of Agriculture of China, Yangzhou University (26116120).

Author Contributions: Zhi-Teng Chen and Yu-Zhou Du designed the experiments; Zhi-Teng Chen performed the experiments, analyzed the data and wrote the paper.

Conflicts of Interest: The authors declare no conflict of interest. The founding sponsors had no role in the design of the study; in the collection, analyses, or interpretation of data; in the writing of the manuscript, and in the decision to publish the results.

\section{Abbreviations}

$\begin{array}{ll}\text { IGN } & \text { Intergenic Nucleotide } \\ \text { PCG } & \text { Protein-Coding Gene } \\ \text { tRNA } & \text { Transfer RNA } \\ \text { rRNA } & \text { Ribosomal RNA } \\ \text { CR } & \text { Control Region } \\ \text { SL } & \text { Stem-Loop } \\ \text { CSB } & \text { Conserved Sequence Block } \\ \text { BI } & \text { Bayesian inferences } \\ \text { ML } & \text { Maximum likelihood }\end{array}$

\section{Appendix A}

Table A1. Sequencing strategy and primers used in this study.

\begin{tabular}{|c|c|c|c|}
\hline Regions & Strategy & LA-PCR Primers $\left(5^{\prime}-3^{\prime}\right)$ & Specific Primers $\left(5^{\prime}-3^{\prime}\right)$ \\
\hline $\operatorname{cox} 1-c y t b$ & $\begin{array}{l}\text { Primer } \\
\text { walking }\end{array}$ & $\begin{array}{l}\text { COI-2F: GGTTGATGCTACCCCTGGACG } \\
\text { COI-4F: TTGATTTCACCCAATATAGAACTAA } \\
\text { Cytb-3R: GGGGATGTGTTATTTGGGTG } \\
\text { Cytb-2R: GAAAGCTAAGTCAATATGGGCA } \\
\text { Cytb-4F: GCCTAATGCCCCCTCACA } \\
\text { COI-5R: TGTTGGGGAAAGTCTTCTATGGA }\end{array}$ & $\begin{array}{l}\text { YP01200761-1F: AGAAGACCGACGAACGCC } \\
\text { YP01200765-1F: CAGCAAAAGGCCCCCACG } \\
\text { YP01200769-1F: CGGTTACAGCAGCACTTCA } \\
\text { YP01200786-1F: CCCTTTTAGACACCACCCTT } \\
\text { YP01200797-1F: TACAGCTGGTAAAAATAGTTCAAA } \\
\text { YP01200760-1R: TTCACACAAGCTGCACGAT } \\
\text { YP01200772-1R: TGTTGGGAAGAGGAATCTAAGA } \\
\text { YP01200773-1R: AACTGCCTGTGGGTATCGT } \\
\text { YP01200783-1R: GCCGAAACCCCCTCCTG } \\
\text { YP01200786-2F: TTGCCATTCCAAACCCAT } \\
\text { YP01200783-1F: TGCGTTCGGCAAGGTAT } \\
\text { YP01200797-1R: GGTTGATGCTACCCCTGG } \\
\text { NJCJ-COI-3F: GATTTATGCCATCACGATACTCA } \\
\text { NJCJ-COI-5F: ATGCTTTATCCCATTTTTCG } \\
\text { NJCJ-Cytb-4R: TTTGGGTTGTGATGTTATTTCTT } \\
\text { NJCJ-COI-5R: TGTTGGGGAAAGTCTTCTATGGA } \\
\text { NJCJ-COI-6F: AAAAGCGGCATATCACTGTT } \\
\text { NJCJ-Cytb-5R: TTGATTGCTTACTCTTCGGTTG } \\
\text { NJCJ-COI-7F: ACCCCAATCAGCCTCCTAA } \\
\text { NJCJ-Cytb-6R: GTTGTTTTTACATTGATTTCCTTT }\end{array}$ \\
\hline$c y t b-\operatorname{cox} 1$ & Shotgun & $\begin{array}{l}\text { Cytb-1F: TTCATCTCCTATTCCTTCACCAAA } \\
\text { COI-1R: GTGATTGCTACGGCTCAAACGAA }\end{array}$ & $\begin{array}{l}\text { YP01190217-1F: TGGTCGGGGTTGCTTTCT } \\
\text { YP01190203-1R: ATAATTTCCCGATTTAAAGAGAG } \\
\text { YP01190233-1R: TTCGTAAGCTACACCTTGACC } \\
\text { YP01190202-1F: GGCACTTCTGCTCTTCCCG } \\
\text { YP01190227-1F: AAAGTCTTCGATCTGTCAGTTGT } \\
\text { YP01190213-2R: CGTAAGAAAAACAATGTTAATATA } \\
\text { YP01190213-3R: ATATATTATATCTATATGGATATTATGTTT } \\
\text { NJCJ-control-1F: TATGGTTCTATATGCAATTTCCTCCC } \\
\text { YP01190213-1R: TAGAGAGAAGAGGGGTAAAAC }\end{array}$ \\
\hline
\end{tabular}




\section{References}

1. Cameron, S.L. Insect mitochondrial genomics: Implications for evolution and phylogeny. Annu. Rev. Entomol. 2014, 59, 95-117. [CrossRef] [PubMed]

2. Simon, C.; Frati, F.; Beckenbach, A.; Crespi, B.; Liu, H.; Flook, P. Evolution, weighting, and phylogenetic utility of mitochondrial gene sequences and a compilation of conserved polymerase chain reaction primers. Ann. Entomol. Soc. Am. 1994, 87, 651-701. [CrossRef]

3. Simon, C.; Buckley, T.R.; Frati, F.; Stewart, J.B.; Beckenbach, A.T. Incorporating molecular evolution into phylogenetic analysis, and a new compilation of conserved polymerase chain reaction primers for animal mitochondrial DNA. Annu. Rev. Ecol. Evol. Syst. 2006, 37, 545-579. [CrossRef]

4. Da Silva, N.M.; de Souza Dias, A.; da Silva Valente, V.L.; Valiati, V.H. Characterization of mitochondrial control region, two intergenic spacers and tRNAs of Zaprionus indianus (Diptera: Drosophilidae). Genetica 2009, 137, 325-332. [CrossRef] [PubMed]

5. Wolstenholme, D.R. Animal mitochondrial DNA: Structure and evolution. Int. Rev. Cytol. 1992, 141, $173-216$. [PubMed]

6. Zhang, D.X.; Szymura, J.M.; Hewitt, G.M. Evolution and structure conservation of the control region of insect mitochondrial DNA. J. Mol. Evol. 1995, 40, 382-391. [CrossRef] [PubMed]

7. Zhang, D.X.; Hewitt, G.M. Insect mitochondrial control region: A review of its structure, evolution and usefulness in evolutionary studies. Biochem. Syst. Ecol. 1997, 25, 99-120. [CrossRef]

8. Beckenbach, A.T.; Stewart, J.B. Insect mitochondrial genomics 3: The complete mitochondrial genome sequences of representatives from two neuropteroid orders: A dobsonfly (order Megaloptera) and a giant lacewing and an owlfly (order Neuroptera). Genome 2009, 52, 31-38. [CrossRef] [PubMed]

9. Saito, S.; Tamura, K.; Aotsuka, T. Replication origin of mitochondrial DNA in insects. Genetics 2005, 171, 1695-1705. [CrossRef] [PubMed]

10. Karr, J.R. Defining and measuring river health. Freshw. Biol. 1999, 41, 221-234. [CrossRef]

11. Chen, Z.T.; Du, Y.Z. Comparison of the complete mitochondrial genome of the stonefly Sweltsa longistyla (Plecoptera: Chloroperlidae) with mitogenomes of three other stoneflies. Gene 2015, 558, 82-87. [CrossRef] [PubMed]

12. Chen, Z.T.; Du, Y.Z. Complete mitochondrial genome of Capnia zijinshana (Plecoptera: Capniidae) and phylogenetic analysis among stoneflies. J. Asia Pac. Entomol. 2017, 20, 305-312. [CrossRef]

13. Chen, Z.T.; Wu, H.Y.; Du, Y.Z. The nearly complete mitochondrial genome of a stonefly species, Styloperla sp. (Plecoptera: Styloperlidae). Mitochondrial DNA Part A 2016, 27, 2728-2729.

14. Elbrecht, V.; Poettker, L.; John, U.; Leese, F. The complete mitochondrial genome of the stonefly Dinocras cephalotes (Plecoptera, Perlidae). Mitochondrial DNA 2015, 26, 469-470. [CrossRef] [PubMed]

15. Huang, M.; Wang, Y.; Liu, X.; Li, W.; Kang, Z.; Wang, K.; Li, X.; Yang, D. The complete mitochondrial genome and its remarkable secondary structure for a stonefly Acroneuria hainana Wu (Insecta: Plecoptera, Perlidae). Gene 2015, 557, 52-60. [CrossRef] [PubMed]

16. Stewart, J.B.; Beckenbach, A.T. Insect mitochondrial genomics 2: The complete mitochondrial genome sequence of a giant stonefly, Pteronarcys princeps, asymmetric directional mutation bias, and conserved plecopteran A+T-region elements. Genome 2006, 49, 815-824. [CrossRef] [PubMed]

17. Qian, Y.H.; Wu, H.Y.; Ji, X.Y.; Yu, W.W.; Du, Y.Z. Mitochondrial genome of the stonefly Kamimuria wangi (Plecoptera: Perlidae) and phylogenetic position of Plecoptera based on mitogenomes. PLoS ONE 2014, 9, e86328.

18. Sproul, J.S.; Houston, D.D.; Nelson, C.R.; Evans, R.P.; Crandall, K.A.; Shiozawa, D.K. Climate oscillations, glacial refugia, and dispersal ability: Factors influencing the genetic structure of the least salmonfly, Pteronarcella badia (Plecoptera), in western North America. BMC Evol. Biol. 2015, 15, 279. [CrossRef] [PubMed]

19. Vasco, E.; Florian, L. The mitochondrial genome of the Arizona Snowfly Mesocapnia arizonensis (Plecoptera, Capniidae). Mitochondrial DNA Part A 2016, 27, 3365-3366.

20. Wu, H.Y.; Ji, X.Y.; Yu, W.W.; Du, Y.Z. Complete mitochondrial genome of the stonefly Cryptoperla stilifera Sivec (Plecoptera: Peltoperlidae) and the phylogeny of Polyneopteran insects. Gene 2014, 537, 177-183. [CrossRef] [PubMed]

21. Wang, K.; Ding, S.; Yang, D. The complete mitochondrial genome of a stonefly species, Kamimuria chungnanshana Wu, 1948 (Plecoptera: Perlidae). Mitochondrial DNA Part A 2016, 27, 3810-3811. [CrossRef] [PubMed] 
22. Wang, K.; Wang, Y.; Yang, D. The complete mitochondrial genome of a stonefly species, Togoperla sp. (Plecoptera: Perlidae). Mitochondrial DNA Part A 2016, 27, 1703-1704.

23. Wang, Y.; Cao, J.; Li, W. The complete mitochondrial genome of the styloperlid stonefly species Styloperla spinicercia Wu (Insecta: Plecoptera) with family-level phylogenetic analyses of the Pteronarcyoidea. Zootaxa 2017, 4243, 125-138. [CrossRef]

24. Zhou, C.; Tan, M.; Du, S.; Zhang, R.; Machida, R.; Zhou, X. The mitochondrial genome of the winter stonefly Apteroperla tikumana (Plecoptera, Capniidae). Mitochondrial DNA Part A 2016, 27, 3030-3032.

25. Clary, D.O.; Wolstenholme, D.R. The ribosomal RNA genes of Drosophila mitochondrial DNA. Nucleic Acids Res. 1985, 13, 4029-4045. [CrossRef] [PubMed]

26. Wei, S.J.; Shi, M.; Chen, X.X.; Sharkey, M.J.; van Achterberg, C.; Ye, G.Y.; He, J.H. New views on strand asymmetry in insect mitochondrial genomes. PLoS ONE 2010, 5, e12708. [CrossRef] [PubMed]

27. Ojala, D.; Montoya, J.; Attardi, G. tRNA punctuation model of RNA processing in human mitochondria. Nature 1981, 290, 470-474. [CrossRef] [PubMed]

28. Garey, J.R.; Wolstenholme, D.R. Platyhelminth mitochondrial DNA: Evidence for early evolutionary origin of a tRNAserAGN that contains a dihydrouridine arm replacement loop, and of serine-specifying AGA and AGG codons. J. Mol. Evol. 1989, 28, 374-387. [CrossRef] [PubMed]

29. Abascal, F.; Posada, D.; Knight, R.D.; Zardoya, R. Parallel evolution of the genetic code in arthropod mitochondrial genomes. PLoS Biol. 2006, 4, 711-718. [CrossRef] [PubMed]

30. Abascal, F.; Posada, D.; Zardoya, R. The evolution of the mitochondrial genetic code in arthropods revisited. Mitochondrial DNA 2012, 23, 84-91. [CrossRef] [PubMed]

31. Crozier, R.H.; Crozier, Y.C. The mitochondrial genome of the honeybee Apis mellifera: Complete sequence and genome organization. Genetics 1993, 133, 97-117. [PubMed]

32. Korkmaz, E.M.; Budak, M.; Ördek, M.N.; Başıbüyük, H.H. The complete mitogenomes of Calameuta filiformis (Eversmann, 1847) and Calameuta idolon (Rossi, 1794) (Hymenoptera: Cephidae): The remarkable features of the elongated A+T rich region in Cephini. Gene 2016, 576, 404-411. [CrossRef] [PubMed]

33. Grant, J.R.; Stothard, P. The CGView Server: A comparative genomics tool for circular genomes. Nucleic Acids Res. 2008, 36, 181-184. [CrossRef] [PubMed]

34. Bernt, M.; Donath, A.; Jühling, F.; Externbrinka, F.; Florentz, C.; Fritzsch, G.; Pützh, J.; Middendorf, M.; Stadler, P.F. MITOS: Improved de novo metazoan mitochondrial genome annotation. Mol. Phylogenet. Evol. 2013, 69, 313-319. [CrossRef] [PubMed]

35. Laslett, D.; Canbäck, B. ARWEN, a program to detect tRNA genes in metazoan mitochondrial nucleotide sequences. Bioinformatics 2008, 24, 172-175. [CrossRef] [PubMed]

36. Tamura, K.; Stecher, G.; Peterson, D.; Filipski, A.; Kumar, S. MEGA6: Molecular evolutionary genetics analysis version 6.0. Mol. Biol. Evol. 2013, 30, 2725-2729. [CrossRef] [PubMed]

37. Perna, N.T.; Kocher, T.D. Patterns of nucleotide composition at fourfold degenerate sites of animal mitochondrial genomes. J. Mol. Evol. 1995, 41, 353-358. [CrossRef] [PubMed]

38. Markham, N.R.; Zuker, M. DINAMelt web server for nucleic acid melting prediction. Nucleic Acids Res. 2005, 33, W577-W581. [CrossRef] [PubMed]

39. Larkin, M.A.; Blackshields, G.; Brown, N.P.; Chenna, R.; McGettigan, P.A.; McWilliam, H.; Valentin, F.; Wallace, I.M.; Wilm, A.; Lopez, R.; et al. ClustalW and ClustalX version 2.0. Bioinformatics 2007, 23, $2947-2948$. [CrossRef] [PubMed]

40. Huelsenbeck, J.P.; Ronquist, F. Mrbayes: Bayesian inference of phylogenetic trees. Bioinformatics 2001, 17, 754-755. [CrossRef] [PubMed]

41. Stamatakis, A. RAxML version 8: A tool for phylogenetic analysis and post-analysis of large phylogenies. Bioinformatics 2014, 30, 1312-1313. [CrossRef] [PubMed]

42. Rambaut, A.; Drummond, A.J. Tracer Version 1.5 2009. Available online: http://tree.bio.ed.ac.uk/software/tracer (accessed on 15 April 2017).

43. Rambaut, A.; Drummond, A.J. FigTree Version 1.4.0 2012. Available online: http://tree.bio.ed.ac.uk/ software/figtree (accessed on 15 April 2017).

(C) 2017 by the authors. Licensee MDPI, Basel, Switzerland. This article is an open access article distributed under the terms and conditions of the Creative Commons Attribution (CC BY) license (http://creativecommons.org/licenses/by/4.0/). 